Return to the Manage Active Submissions page at http://spie.org/app/submissions/tasks.aspx and approve or disapprove this submission. Your manuscript will not be published without this approval. Please contact author help@spie.org with any questions or concerns.

\title{
Finite element model updating of a RC building considering seismic response trends
}

\author{
F. Butt ${ }^{\mathrm{a}, \mathrm{b}}, \mathrm{P}$. Omenzetter ${ }^{* \mathrm{c}}$ \\ ${ }^{\mathrm{a}}$ Department of Civil \& Environmental Engineering, The University of Auckland, Private Bag \\ 92019, Auckland 1142, New Zealand \\ ${ }^{\mathrm{b}}$ Department of Civil Engineering, University of Engineering and Technology, Taxila 47050, \\ Pakistan \\ ${ }^{\mathrm{c}}$ The LRF Centre for Safety and Reliability Engineering, University of Aberdeen, \\ Aberdeen, AB24 3UE, UK
}

\begin{abstract}
This paper presents a study on the seismic response trends evaluation and finite element model updating of a reinforced concrete building monitored for a period of more than two years. The three story reinforced concrete building is instrumented with five tri-axial accelerometers and a free-field tri-axial accelerometer. The time domain N4SID system identification technique was used to obtain the frequencies and damping ratios considering flexible base models taking into account the soil-structure-interaction using 50 earthquakes. Trends of variation of seismic response were developed by correlating the peak response acceleration at the roof level with identified frequencies and damping ratios. A general trend of decreasing frequencies was observed with increased level of shaking. To simulate the varying behavior of the building with response levels, a series of three dimensional finite element models were calibrated considering several points on the developed frequency-response amplitude trend lines as targets for updating. To incorporate real in-situ conditions, soil underneath the foundation and around the building was modeled using spring elements and nonstructural components (claddings and partitions) were also included. Sensitivity based model updating technique was applied taking into account concrete, soil and cladding stiffness as updating parameters. It was concluded from the investigation that knowledge of the variation of seismic response of buildings is necessary to better understand their behavior during earthquakes, and also that the participation of soil and non-structural components is significant towards the seismic response of the building and these should be considered in models to simulate the real behavior.
\end{abstract}

Keywords: Instrumented RC building, structural health monitoring, seismic response, system identification, model updating, soil-structure-interaction

\section{INTRODUCTION}

The full scale, in-situ investigations of instrumented buildings present an excellent opportunity to observe their dynamic response in as-built environment, which includes all the real physical properties of a structure under study and its environment. Previous studies have shown that the dynamic characteristics tend to vary with vibration amplitude ${ }^{1-3}$. It is, therefore, important to investigate the behavior of buildings under different excitation scenarios. The trends of variation of dynamic characteristics, including modal frequencies and damping ratios, thus developed will provide quantitative data for the variations in the behavior of buildings. Moreover, such studies will provide invaluable information for the development and calibration of realistic models for the prediction of seismic response of structures in model updating and structural health monitoring studies ${ }^{4,5}$. An important factor in the modeling of civil engineering structures is the effect of soil-structure-interaction (SSI). SSI involves transfer of energy from the ground to the structure and back to the ground $^{6}$. Another important factor is consideration of non-structural components (NSCs) such as cladding, partition walls. These factors, if modeled adequately in FEMs, can affect dynamic simulations ${ }^{7,8}$. Proper modeling of SSI and NSCs is, therefore, necessary to better predict the actual response of structures.

This study comprises two parts. In the first part, seismic response trends of an instrumented RC building under 50 earthquakes were evaluated. For this purpose, relationships between natural frequencies and damping ratios with peak

*piotr.omenzetter@abdn.ac.uk; phone 441224 272529; fax 441224 272497; www.abdn.ac.uk 
Return to the Manage Active Submissions page at http://spie.org/app/submissions/tasks.aspx and approve or disapprove this submission. Your manuscript will not be published without this approval. Please contact author_help@spie.org with any questions or concerns.

response acceleration (PRA) at the roof were statically examined. Natural frequencies and damping ratios, accounting for SSI, were identified using the state-of-the-art N4SID system identification technique. For natural input modal analysis, this technique is considered to belong to the most powerful class of the known system identification techniques in the time domain?

The second part of this study comprises the development and updating of a series of FEMs of the building incorporating the soil flexibility and non-structural components (NSCs). The FEM is updated using a sensitivity based technique considering several points on the developed trends as targets for updating routines. The study attempts to highlight the importance of modeling soil and NSCs and replicating the actual varying behavior under seismic excitations to simulate the real behavior of structures. The outcome of the two aforementioned studies is expected to further the understanding of dynamic behavior of buildings during earthquakes and provide new quantitative data for studying seismic responses of as-built structures, structural health monitoring and model updating.

\section{DESCRIPTION OF THE BUILDING AND INSTRUMENTATION}

The building under study is situated at Lower Hutt approximately $20 \mathrm{~km}$ north-east of Wellington, New Zealand. It is a three story RC structure with a basement, $44 \mathrm{~m}$ long, $12.19 \mathrm{~m}$ wide and $13.4 \mathrm{~m}$ high (measured from the base level). The structural system consists of 12 beam-column frames and a $2.54 \times 1.95 \mathrm{~m}$ RC shear core with the wall thickness of $229 \mathrm{~mm}$, which houses an elevator. The plan of the building is rectangular but the shear core and, to a lesser extent, additional beams along the longitudinal direction inside the perimeter beams and staircase make it unsymmetrical in terms of stiffness distribution (Figure 1a). The exterior beams are $762 \times 356 \mathrm{~mm}$ except at the roof level where these are $1067 \times 356 \mathrm{~mm}$. All the interior beams and all the columns are $610 \times 610 \mathrm{~mm}$. Floors are $127 \mathrm{~mm}$ thick reinforced concrete slabs except a small portion of the ground floor near the stairs where it is $203 \mathrm{~mm}$ thick. The roof comprises corrugated steel sheets over timber planks supported by steel trusses. The building is resting on separate pad type footings of base dimensions $2.29 \times 2.29 \mathrm{~m}$ at the perimeter and $2.74 \times 2.74 \mathrm{~m}$ inside the perimeter and $610 \times 356 \mathrm{~mm}$ tie beams are provided to join all the footings together. This building is instrumented with five tri-axial accelerometers. Two accelerometers are fixed at the base level, one underneath the first floor slab, and two at the roof level as shown in Figure 1b. There is also a free field tri-axial accelerometer mounted at the ground surface and located $39.4 \mathrm{~m}$ from the south end of the building. Figure 1 also shows the common global axes $\mathrm{x}$ and $\mathrm{y}$ used for identifying directions in the subsequent discussions.
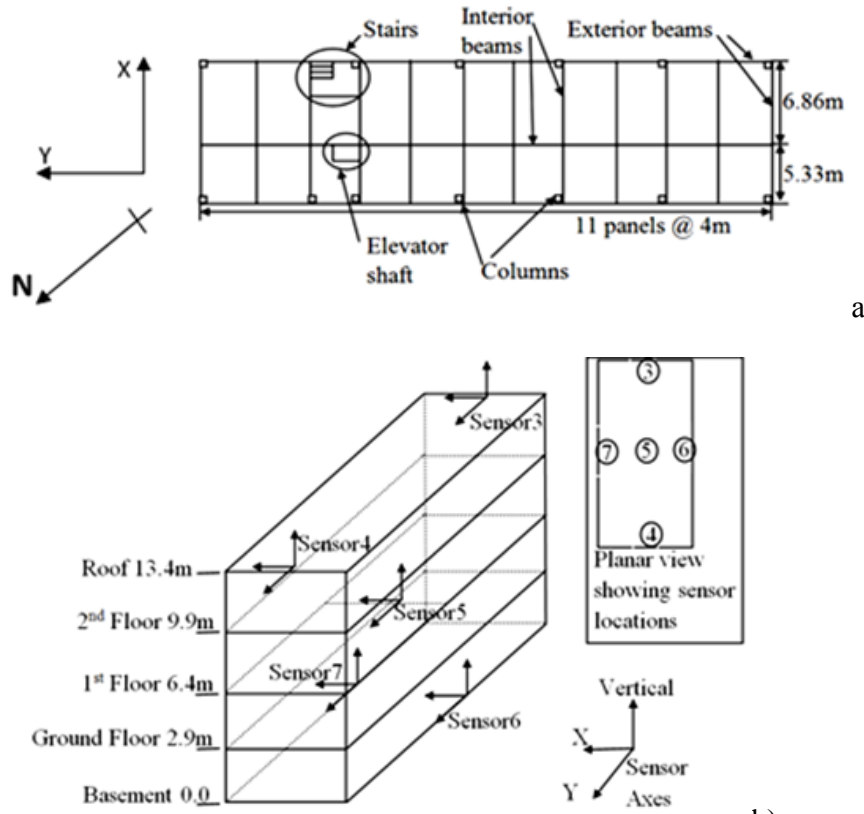

a)

b)

Figure 1. a) Typical floor plan showing general dimensions and location of stairs and elevator shaft, and b) Sensor array. 
Return to the Manage Active Submissions page at http://spie.org/app/submissions/tasks.aspx and approve or disapprove this submission. Your manuscript will not be published without this approval. Please contact author_help@spie.org with any questions or concerns.

\section{SYSTEM IDENTIFICATION FOR EVALUATING SSI EFFECTS}

This section provides a brief explanation of the N4SID system identification technique, its application to the building and evaluating SSI effects using N4SID technique. After sampling of a continuous time state space model, the discrete time state space model can be written as:

$$
\begin{aligned}
& \boldsymbol{x}_{k+1}=\boldsymbol{A} \boldsymbol{x}_{k}+\boldsymbol{B} \boldsymbol{u}_{k}+\boldsymbol{w}_{k} \\
& \boldsymbol{y}_{k}=\boldsymbol{C} \boldsymbol{x}_{k}+\boldsymbol{D} \boldsymbol{u}_{k}+\boldsymbol{v}_{k}
\end{aligned}
$$

where $\boldsymbol{A}, \boldsymbol{B}, \boldsymbol{C}$ and $\boldsymbol{D}$ are the discrete time state, input, output and feedthrough matrices, respectively, whereas $\boldsymbol{x}_{k}$ and $\boldsymbol{y}_{k}$ are the state and output vectors and $\boldsymbol{u}_{k}$ is the excitation vector, respectively. Vectors $\boldsymbol{w}_{k}$ and $\boldsymbol{v}_{k}$ are the process and measurement noise, respectively, that are always present in real-life applications. The identification involves two steps. The first step takes projections of certain subspaces calculated from input and output observations (in the block Hankel matrix) to estimate the state sequence of the system. In the second step, a least square problem is solved to estimate the system matrices $\boldsymbol{A}, \boldsymbol{B}, \boldsymbol{C}$ and $\boldsymbol{D}$. Then the modal parameters, i.e. natural frequencies, damping ratios and mode shapes, are found by eigenvalue decomposition of the system matrix $\boldsymbol{A}$. Full details of the technique can be found in Van Overschee and De Moor ${ }^{10}$.

To avoid spurious results, the approach based on observing trends of the estimated modal parameters in the so-called stabilization charts (Figure 2) is often used: a range of system orders is tried and modal parameters which repeat themselves across that range are accepted as correct results. Stability tolerances are chosen based on the relative change in the modal properties, i.e. modal frequencies, damping ratios and mode shapes, of a given mode as the system order increases. For mode shapes stability, model assurance criterion (MAC) between the mode shapes of the present and previous orders was examined. MAC is an index that determines the similarity between two mode shapes. For modes $\phi_{i}$ and $\phi_{j}$, MAC is defined as ${ }^{11}$ :

$$
M A C=\frac{\left(\boldsymbol{\phi}_{i}^{T} \boldsymbol{\phi}_{j}\right)^{2}}{\left(\boldsymbol{\phi}_{i}^{T} \boldsymbol{\phi}_{i}\right)\left(\boldsymbol{\phi}_{j}^{T} \boldsymbol{\phi}_{j}\right)}
$$

In Equation (3), superscript $T$ denotes vector transpose.

For evaluation of SSI effects using system identification procedures, Stewart and Fenves ${ }^{12}$ proposed the following approach. Consider structure shown in Figure 2. The height $h$ is the vertical distance from the base to the roof (or another measurement point located on the building). The symbols denoting translational displacements are as follows: $u_{g}$ for the free field translational displacement, $u_{f}$ for the foundation translational displacement with respect to the free field, and $u$ for the roof translational displacement with respect to the foundation. Foundation rocking angle is denoted by $\theta$, and its contribution to the roof translational displacement is $h \theta$. The Laplace domain counterparts of these quantities will be denotes as $\hat{u}_{g}, \hat{u}_{f}, \hat{u}$ and $\hat{\theta}$, respectively.

Stewart and Fenves ${ }^{12}$ consider, among others, the flexible base model and associated transfer functions $H$ as follows:

$$
H=\frac{\hat{u}_{g}+\hat{u}_{f}+\hat{u}+h \hat{\theta}}{\hat{u}_{g}}
$$

where input is the free field acceleration and output is the total roof displacement $u_{g}+u_{f}+u+h \theta$.

In this study, we have considered the flexible base model to ascertain the dynamic behavior (frequencies, damping ratios and mode shapes) of the building including SSI. Stewart and Fenves ${ }^{12}$ demonstrate that the poles of the flexible base transfer function $H$ give natural frequencies and damping ratios of the entire dynamical system comprising the structure, foundation and soil. In other words, the identified modal parameters are influenced by the translational and rotational stiffness and damping of soil. To provide a simple quantification of the effects of SSI on the response of the building, in this study modal vibration parameters were sought through N4SID technique for the flexible base case using input-output pairs consisting of a combination of free field, foundation and superstructure level recordings as explained in Equation (4). For the building under study, sensor 10 (the free field sensor) was considered as the input and sensors 3, 4, 5, 6 and 7 as the outputs for the flexible base case. 
Return to the Manage Active Submissions page at http://spie.org/app/submissions/tasks.aspx and approve or disapprove this submission. Your manuscript will not be published without this approval. Please contact author_help@spie.org with any questions or concerns.

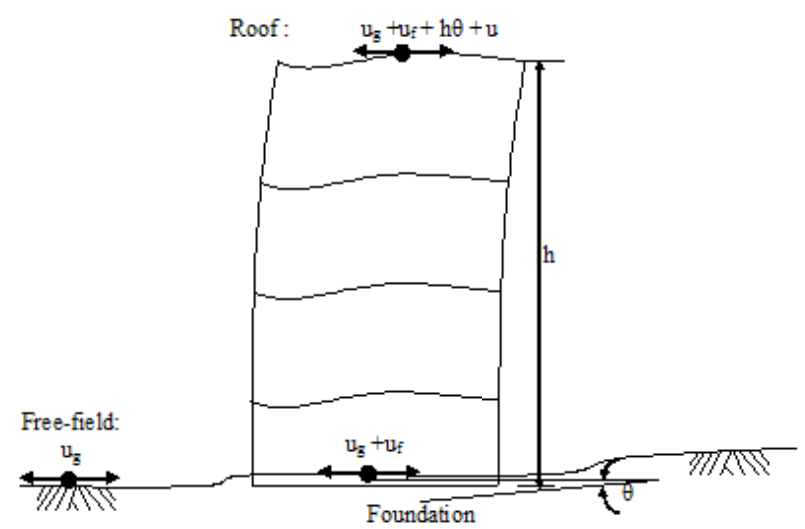

Figure 2. Inputs and outputs for evaluating SSI effects in system identification of buildings ${ }^{12}$.

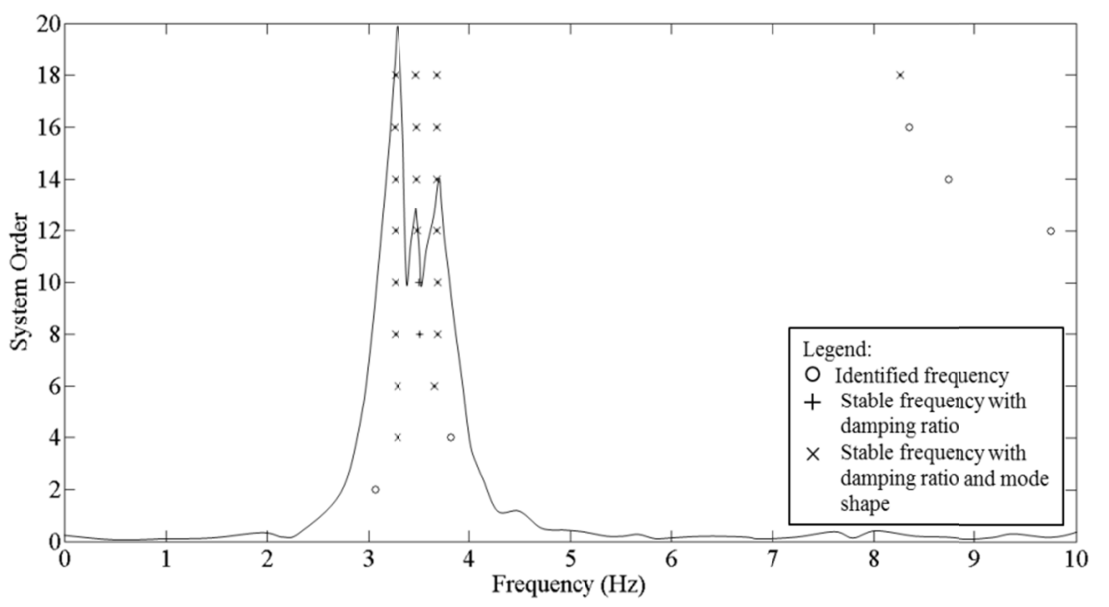

Figure 3. Typical stabilization chart showing stable modes.

\section{EVALUATION OF SEISMIC RESPONSE TRENDS INCLUDING SSI}

The objective of this part of research is to assess and understand the seismic response of the building under a large number of earthquakes. In particular, trends are investigated between PRA and the identified first three natural frequencies and corresponding damping ratios under a large number of earthquakes. For this study, 50 earthquakes recorded on the building which had epicenters within $200 \mathrm{~km}$ were selected. The reason for adopting this was to select earthquakes of such an intensity which can excite the modes of interest with acceptable signal-to-noise ratios providing quality system identification results. The area surrounding the buildings had not been hit by any strong earthquake since their instrumentation. The majority, i.e. 44 of the 50 recorded earthquakes, have a Richter magnitude ranging from 3 to 5 , except only six that have more than 5 , with 5.2 being the maximum value. This means that nearly all of the earthquakes fall into the category of low intensity except a very few that can be treated as moderate events.

Table 1 summarizes maximum accelerations recorded at the free field, base and roof sensors for the 50 earthquakes. The maximum PGA at the free field sensor 10 was recorded along Y-direction $(0.0138 \mathrm{~g})$ and was almost double the maximum along X-direction $(0.0074 \mathrm{~g})$. The maximum PGA at the base of the building was $0.0093 \mathrm{~g}$ and was captured by sensor 6 along Y-direction, and was a little higher than the maximum PGA recorded by sensor 7 along Y-direction $(0.0090 \mathrm{~g})$. Along the X-direction, sensor 7 recorded a slightly higher maximum PGA $(0.0061 \mathrm{~g})$ than sensor $6(0.0059 \mathrm{~g})$.

The maximum PRA of the building in the Y-direction was $0.041 \mathrm{~g}$ captured by sensor 4 , which was double the maximum recorded acceleration in the X-direction of $0.021 \mathrm{~g}$. For sensor 3, the maximum PRA was almost the same $(0.040 \mathrm{~g})$ as that of sensor 4 along the Y-direction and almost double the maximum PRA acceleration in the X-direction $(0.019 \mathrm{~g})$. It should be noted, however, that the majority (94\%) of analyzed earthquakes resulted in PRAs below $0.015 \mathrm{~g}$ (this will also be seen clearly later in Figures 5 and 6). 
Return to the Manage Active Submissions page at http://spie.org/app/submissions/tasks.aspx and approve or disapprove this submission. Your manuscript will not be published without this approval. Please contact author_help@spie.org with any questions or concerns.

Table 1. Maximum PGA and PRA recorded by individual sensors.

\begin{tabular}{|c|c|c|}
\hline Sensor & $\begin{array}{l}\text { Max. acceleration } \\
\text { in X-direction (g) }\end{array}$ & $\begin{array}{l}\text { Max. acceleration } \\
\text { in Y-direction (g) }\end{array}$ \\
\hline 10 (PGA) & 0.0074 & 0.0138 \\
\hline 6 (PGA) & 0.0059 & 0.0093 \\
\hline 7 (PGA) & 0.0061 & 0.0090 \\
\hline 3 (PRA) & 0.019 & 0.040 \\
\hline 4 (PRA) & 0.021 & 0.041 \\
\hline
\end{tabular}

\subsection{Modal identification of the instrumented building}

This subsection reports the results of the analysis using the selected 50 earthquake records and performs system identification of modal parameters of the building. The identified natural frequencies and damping ratios are plotted against PRAs and their trends are statistically evaluated. N4SID technique was used to identify the first three frequencies, corresponding damping ratios and mode shapes. Sampling rate of the digitized signal was $200 \mathrm{~Hz}$ and for establishing stabilization charts system orders from 2 to 20 were considered. A typical stabilization chart is shown in Figure 3: the marker 'o' shows all the identified frequencies, ' + ' shows stable frequencies and damping ratios, while ' $\times$ ' stable frequencies, damping ratios and mode shapes. In this research, an identified frequency was considered to be stable if the absolute deviation between the frequency identified at the present and previous order was less than or equal to $0.01 \mathrm{~Hz}$. A stable damping ratio was defined by an absolute deviation less than $5 \%$. For mode shapes stability, the MAC between the mode shapes of the present and previous order was to be at least $90 \%$ or greater. It can be seen in Figure 3 that three modes can be identified with confidence and subsequent discussions focus on these.

The typical first three mode shapes of the building for flexible base models are shown in Figure 4 in planar view. (Note that because of a limited number of measurement points those graphs assume the floors were rigid diaphragms.) The shape of the first mode shows it to be a translational mode along X-direction with some torsion. The second mode is nearly purely torsional, and the third one is translationally dominant along Y-direction coupled with torsion. Structural irregularities, such as those due to the shear core, staircase and internal longitudinal beams, create unsymmetrical distribution of stiffness which has caused the modes to be coupled translational-torsional. Another plausible source of mode shape coupling may be varying soil stiffness under different foundations and around different parts of the building; however, in all numerical simulations presented later such spatial soil variability is ignored.

\subsection{Modal frequency dependence on PRA}

Table 2 shows the minimum, maximum, average and relative range (= (maximum-minimum)/average $\times 100 \%)$ values of the identified modal frequencies for the analyzed 50 earthquakes for the flexible base model. The average first three modal frequencies for the building are $3.33 \mathrm{~Hz}, 3.61 \mathrm{~Hz}$ and $3.79 \mathrm{~Hz}$ and the percentage changes in the first three frequencies are $14 \%, 19 \%$ and $11 \%$ respectively. It is of interest to explore whether, and if so how, those changes in frequencies correlate with response magnitude. Figures 5a-c show the results of modal frequency identification for the analyzed 50 earthquakes. The frequencies are plotted against the resultant PRAs (i.e. magnitudes of the vectorial sum of the horizontal X- and Y-direction components) of a representative roof sensor (sensor 3). In order to quantify relationships between PRAs and modal frequencies linear regression ${ }^{13}$ was applied. It can be observed that the frequencies initially drop at a faster rate with increasing PRAs but later the slope is smaller, and hence bi-linear relation
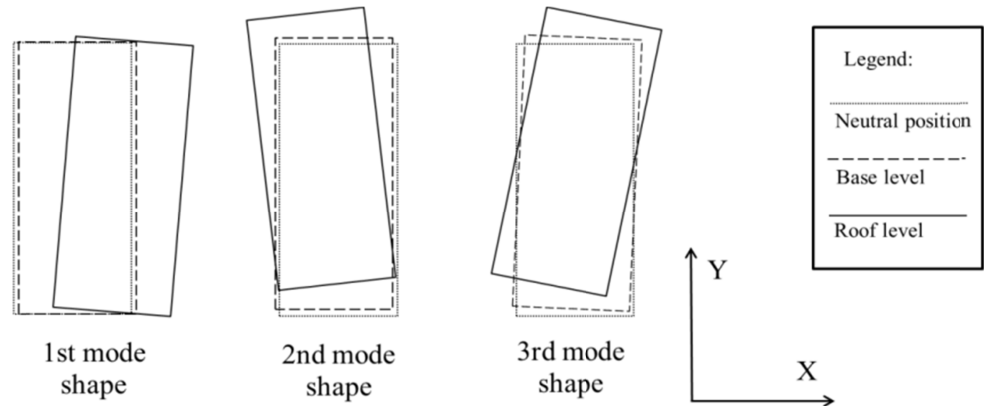

Figure 4. Planar views of the first three mode shapes of the building for flexible base model. 
Return to the Manage Active Submissions page at http://spie.org/app/submissions/tasks.aspx and approve or disapprove this submission. Your manuscript will not be published without this approval. Please contact author_help@spie.org with any questions or concerns.

-ships seem suitable and consequently were applied. In Figures 5a-c the formulas relating the identified modal frequencies and PRA are listed. The negative values of the linear terms confirm again the decreasing trend of modal frequencies with increasing PRA. The strength of correlations of the variables is illustrated by $R^{2}$ or coefficient of determination ${ }^{14}$. The coefficients of determination vary from 0.30 to 0.64 indicating that bilinear relationships fit the data reasonably well. (The coefficient of determination of 0.99 in Figure $6 \mathrm{c}$ was ignored as it was obtained for a line fitted to only two points.)

\subsection{Modal damping ratio dependence on PRA}

Table 2 also shows the minimum, maximum, average and relative range of the identified modal damping ratios for the analyzed 50 earthquakes for flexible base model. The average values of damping ratios for the first, second and third modes are $3.4 \%, 5.6 \%$ and $3.1 \%$. It can be noticed that the identified damping ratios show considerable scatter for both buildings - the relative ranges were between $176 \%$ and $240 \%$. Figures $6 a-c$ show the results of modal damping ratio identification for the analyzed 50 earthquakes. Like the modal frequencies previously, the damping ratios are plotted against resultant PRAs of sensor 3. The scatter of results is now clearly revealed in the figures. No clear trends in damping ratios could be discerned.

\section{MODEL CALIBRATION USING SENSITIVITY BASED MODEL UPDATING}

This section describes briefly the methodology involved in model updating using a sensitivity based technique. Model updating is concerned with calibration of an FEM of a structure such that it can predict the measured responses of that structure. The sensitivity based model updating procedure generally comprises of three aspects: (i) selection of responses as reference data, (ii) selection of parameters to update, and (iii) an iterative model tuning. Inı sensitivity based updating, corrections/modifications are applied to the local physical parameters (geometric, material and boundary and connectivity conditions) of the FEM to modify it with respect to the reference (experimental) data which is in the form of measured modal frequencies and mode shapes. For parameter modification in FEM, the experimental responses are expressed as functions of analytical responses (from FEM), structural parameters and a sensitivity coefficient matrix. In terms of the first order Taylor series it can be expressed as:

$$
\boldsymbol{R}_{e}=\boldsymbol{R}_{a}+\boldsymbol{S}\left(\boldsymbol{P}_{u}-\boldsymbol{P}_{o}\right)
$$

where $\boldsymbol{R}_{\boldsymbol{e}}$ and $\boldsymbol{R}_{\boldsymbol{a}}$ are the vectors of experimental and analytical response values, respectively, whereas $\boldsymbol{P}_{\boldsymbol{u}}$ and

Table 2. Summary of identified frequencies and damping ratios.

\begin{tabular}{|c|c|c|c|c|c|c|c|c|}
\hline \multirow[b]{2}{*}{ Mode } & \multicolumn{4}{|c|}{ Frequency $(\mathrm{Hz})$} & \multicolumn{4}{|c|}{ Damping ratios (\%) } \\
\hline & Min. & Max. & Avg. & $\begin{array}{l}\text { Relative } \\
\text { range }\end{array}$ & Min. & Max. & Avg. & $\begin{array}{l}\text { Relative } \\
\text { range }\end{array}$ \\
\hline $1^{\mathrm{st}}$ & 3.04 & 3.50 & 3.33 & $14 \%$ & 1.2 & 7.3 & 3.4 & $176 \%$ \\
\hline $2^{\text {nd }}$ & 3.21 & 3.88 & 3.61 & $19 \%$ & 1.4 & 12.1 & 5.6 & $190 \%$ \\
\hline $3^{\text {rd }}$ & 3.48 & 3.90 & 3.79 & $11 \%$ & 1.0 & 8.3 & 3.1 & $240 \%$ \\
\hline
\end{tabular}

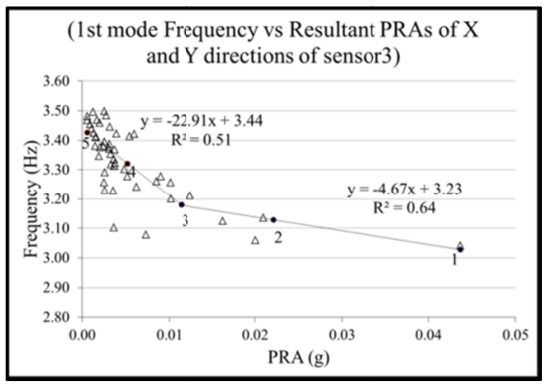

a)

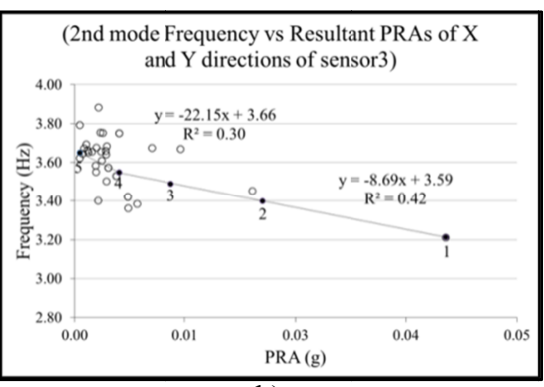

b)

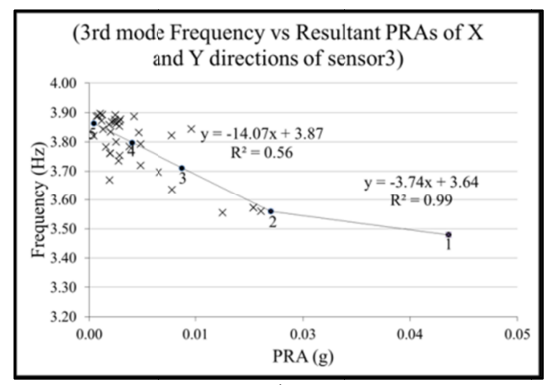

c)

Figure 5. Modal frequencies of the building vs. PRAs of sensor 3: a) $1^{\text {st }}$ mode, b) $2^{\text {nd }}$ mode, and c) $3^{\text {rd }}$ mode. 
Return to the Manage Active Submissions page at http://spie.org/app/submissions/tasks.aspx and approve or disapprove this submission. Your manuscript will not be published without this approval. Please contact author_help@spie.org with any questions or concerns.

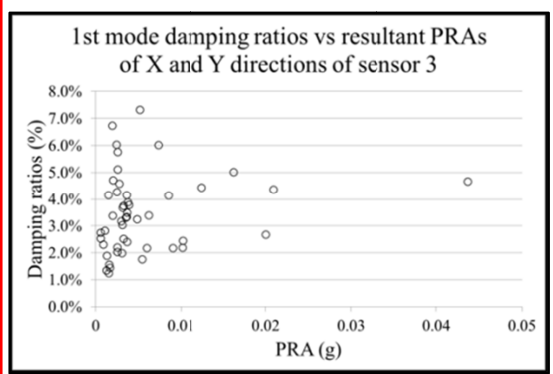

a)

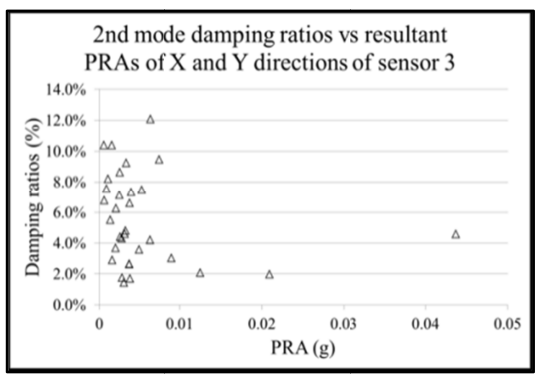

b)

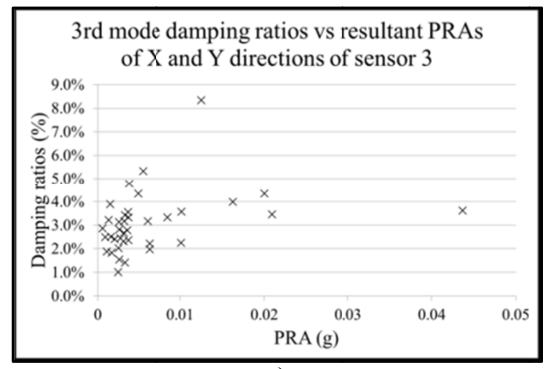

c)

Figure 6. Modal damping ratios of the building vs. PRAs of sensor 3 for flexible base case: a) $1^{\text {st }}$ mode, b) $2^{\text {nd }}$ mode, and c) $3^{\text {rd }}$ mode.

$\boldsymbol{P}_{\boldsymbol{o}}$ are vectors of updated and current parameters, respectively, and $\boldsymbol{S}$ is the sensitivity matrix which can be calculated as:

$$
\boldsymbol{S}_{i j}=\left.\frac{\partial \boldsymbol{R}_{a, i}}{\partial \boldsymbol{P}_{j}}\right|_{\boldsymbol{P}=\boldsymbol{P}_{0}}
$$

Here $\boldsymbol{R}_{\boldsymbol{a}, \boldsymbol{i}}(\mathrm{i}=1$ , n) and $\boldsymbol{P}_{\boldsymbol{u}, j}(\mathrm{j}=1$,

m) are the entries of the analytical structural response and the updating structural parameter vectors, respectively. Equation (6) calculates absolute sensitivities expressed in the units of the response and parameter values. For comparing relative sensitivities of different types of responses to relative changes in different parameters the relative normalized sensitivity matrix $\boldsymbol{S}_{n r}$ can be calculated as ${ }^{15}$ :

$$
\boldsymbol{S}_{n r}=\boldsymbol{R}_{D, a}^{-1} \boldsymbol{S} \boldsymbol{P}_{D}
$$

where $\boldsymbol{R}_{\boldsymbol{D}, \boldsymbol{a}}$ and $\boldsymbol{P}_{\boldsymbol{D}, \boldsymbol{u}}$ are square, diagonal matrices holding response and parameter values, respectively. In this study, a Bayesian parameter estimation technique is used for updating the model with respect to the measured responses. This technique includes weighting coefficients applied to the updating parameters and experimental responses to accommodate the confidence levels in their estimation. The advantage of Bayesian estimation is better conditioning of the updating problem ${ }^{16,17}$. The difference between the experimental and model responses is resolved by using the following updating algorithm ${ }^{18}$ :

$$
\boldsymbol{P}_{u}=\boldsymbol{P}_{0}-\boldsymbol{G}\left(\boldsymbol{R}_{\boldsymbol{e}}-\boldsymbol{R}_{\boldsymbol{a}}\right)
$$

where $\boldsymbol{G}$ is the gain matrix which can be computed as:

$$
\begin{gathered}
\boldsymbol{G}=\left(\boldsymbol{C}_{a}+\boldsymbol{S}_{n r}^{T} \boldsymbol{C}_{e} \boldsymbol{S}_{n r}\right)^{-1} \boldsymbol{S}_{n r}^{T} \boldsymbol{C}_{e} \\
\boldsymbol{G}=\boldsymbol{C}_{a}^{-1} \boldsymbol{S}_{n r}^{T}\left(\boldsymbol{C}_{e}^{-1}+\boldsymbol{S}_{n r} \boldsymbol{C}_{a}^{-1} \boldsymbol{S}_{n r}^{T}\right)^{-1}
\end{gathered}
$$

Equation (9) is valid for the case when the number of responses is not less than the number of updating parameters, whereas Equation (10) is used in the case of fewer responses than the updating parameters. Here, $\boldsymbol{C}_{\boldsymbol{e}}$ and $\boldsymbol{C}_{a}$ represent diagonal weighting matrices expressing the confidence in the values of experimental and model responses, respectively, and superscript $T$ denotes matrix transpose.

Sensitivity analysis comprises of studying the relative difference in frequencies and modal shapes of the analytical and experimental responses. Target parameters $\boldsymbol{R}_{\boldsymbol{e}}$ (experimental response values) are usually the natural frequencies and mode shapes measured from the real structure, whereas updating parameters $\boldsymbol{P}$ are uncertain parameters modeled in FEM which can include geometric and material properties or boundary and connectivity conditions. The important issues regarding the parameter selection are the number of parameters to be updated and preference of certain parameters among many candidates because they are influential based on the sensitivity analysis ${ }^{19}$. Also, the selected parameters should be uncertain and expected to vary, otherwise blindly updated parameters will result in physically meaningless results. One way to avoid such situation is to apply upper and lower bounds to the updating parameters. If there are a number of candidate parameters available for updating then a good way to start is to perform sensitivity analysis for all and compute relative sensitivities (Equation (7)) and retain only those that are influential. 
Return to the Manage Active Submissions page at http://spie.org/app/submissions/tasks.aspx and approve or disapprove this submission. Your manuscript will not be published without this approval. Please contact author help@spie.org with any questions or concerns.

\section{DEVELOPING AND UPDATING FEM CONSIDERING SEISMIC RESPONSE TRENDS}

This section describes the development of a series of FEMs and application of the sensitivity base model updating technique for replicating the varying behavior of the building under seismic excitation. A three dimensional FEM of the instrumented building was developed in the FEMtools software ${ }^{17}$ using the available structural drawings and at-site measurements. Beams and columns were modeled as two nodes LINE2 elements, and slabs, stairs, shear core, cladding and roof steel sheeting as four node QUAD4 elements. The density and modulus of elasticity of concrete for all the elements were taken as $2400 \mathrm{~kg} / \mathrm{m}^{3}$ and $30 \mathrm{GPa}$, respectively. The steel density and modulus of elasticity were taken as $7800 \mathrm{~kg} / \mathrm{m}^{3}$ and $200 \mathrm{GPa}$, respectively. The steel trusses present at the roof level were modeled as equivalent steel beams. The masses of the timber purlins, planks and corrugated steel sheets were calculated and lumped at the equivalent steel beams. All the dead and superimposed loads were applied as area loads or line loads at their respective positions.

Since the structure under study is an office building, there are a large number of partition walls present. The stiffness values of gypsum wall partitions were taken from Kanvinde and Deierlein ${ }^{20}$ as $2800 \mathrm{kN} / \mathrm{m}$ and were modeled as twonode spring elements along the diagonal directions. The mass due to partition walls, false ceilings, attachments, furniture and live loads were collectively applied at the floor slabs as area mass of $450 \mathrm{~kg} / \mathrm{m}^{2}$. External cladding in the building is made up of fiberglass panels with insulating material on the inner side. The density and modulus of elasticity values of fiberglass were taken as $1750 \mathrm{~kg} / \mathrm{m}^{3}$ and $10 \mathrm{GPa}$, respectively, from literature ${ }^{21}$ and their mass was calculated manually $(100 \mathrm{~kg} / \mathrm{m})$ and applied at the perimeter beams.

Soil-structure-interaction at the base is idealized as six DOFs springs along three translations and rotations. The partial submersion of the building is idealized as springs at mid height of the basement columns. For the column springs along the longitudinal and lateral directions one translation DOF only, i.e. stiffness and damping coefficients, along $\mathrm{X}$ and $\mathrm{Y}$ direction, respectively, were taken into account, while for the corner column springs both $\mathrm{X}$ and $\mathrm{Y}$ translation stiffness and damping coefficients were considered. The soil interaction underneath the tie beams is idealized as translational springs along two horizontal and a vertical direction. The values of spring stiffness and damping coefficients were calculated using the procedure explained in Gazetas ${ }^{22}$. Soil present at the site is classified according to the New Zealand Standard NZS1170 23 as class D (deep or soft soil). The shear wave velocity was taken as $160 \mathrm{~m} / \mathrm{s}$ based on the investigation for the site subsoil classification ${ }^{24}$ and the correspondingly dynamic shear modulus as $47 \mathrm{GPa}$. Figure 7 shows the three dimensional FEM having structural and non- structural elements (cladding, partition walls, and stairs) and soil flexibility modeled.

To vary soil stiffness during model updating, only the shear modulus was changed. This was done in order to keep the number of updating parameters small and simplify the calculation of sensitivities of natural frequencies to soil stiffness. The dynamic stiffness modification factors in Gazetas equations ${ }^{22}$ depend on the frequency of foundation motion. A quick check of their values in the frequency range from $2.5 \mathrm{~Hz}$ to $4.0 \mathrm{~Hz}$, encompassing with some margin the full range of frequencies encountered in this study, showed a very small maximum relative variation of less than $1 \%$. For this reason the frequency dependence of soil stiffness was ignored and constant values corresponding to $3.04 \mathrm{~Hz}$ (the lowest modal frequency observed experimentally in Table 2) adopted.

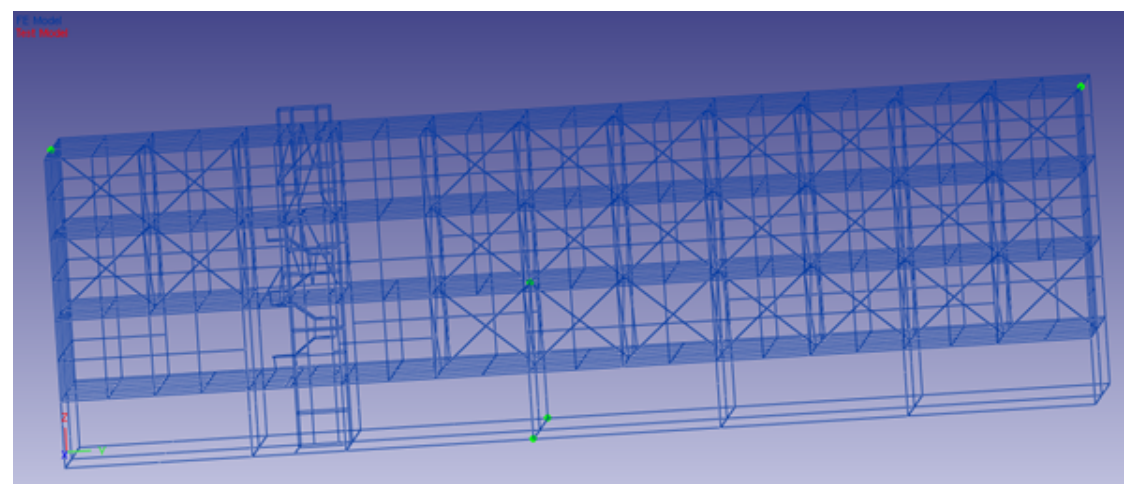

Figure 7. Three dimensional FEM of the building showing stairs, shear core and partition walls (cladding removed from the view to show the inner details). 
Return to the Manage Active Submissions page at http://spie.org/app/submissions/tasks.aspx and approve or disapprove this submission. Your manuscript will not be published without this approval. Please contact author_help@spie.org with any questions or concerns.

Five points were selected on each of the bilinear frequency vs. PRA plots (see Figures 5a-c) in such a way that the whole range of PRAs was covered. The points are also marked on the frequency vs. PRA trend lines in Figures 6a-c. The model updating routine started from Point 1 and concluded at Point 5. An updated FEM for a point served as an initial FEM for the next target point. In the model updating procedure, error interpreted as an objective function is minimized to improve the response prediction of the model. The following objective function, representing mean weighted absolute relative frequency error, is considered in this study:

$$
e_{f}=\frac{1}{n} \sum_{i=1}^{n} c_{r_{i}} \frac{\left|\Delta f_{i}\right|}{f_{i}} \times 100 \%
$$

where $n$ is the total number of target frequencies considered, and $f_{i}$ and $\Delta f_{i}$ are the target frequency and frequency error, respectively, whereas coefficients $c_{r i}$ account for the estimated relative variabilities of responses.

The automatic iterative procedure for minimizing the objective function is controlled by a following three convergence criteria:

i) the minimum value of objective function, assumed $0.1 \%$

ii) the minimum improvement in the objective function between two consecutive iterations, assumed $0.01 \%$, and

iii) the maximum number of iterations allowed, assumed 50.

The algorithm searching for the global minimum of the objective function may be lured into local minima instead of the global minimum. This undesirable behavior is well known in the context of model updating using sensitivity method. In this study, a two-step updating strategy was followed to safeguard against being trapped in a local minimum ${ }^{4}$ :

- Step 1: Starting with the initially assumed values of updating parameters the objective function is minimized to arrive at an intermediate solution.

- Step 2: The values of the updated parameters obtained in Step 1 are perturbed by $+10 \%, 0 \%$ and $-10 \%$, considering all 27 combinations, and the updating procedure rerun.

- The best of the 27 solutions is chosen as the final. This will typically be the one that gives the smallest value of the objective function but careful judgment still needs to be exercised to avoid physically unacceptable solutions.

\subsection{Sensitivity analysis and selection of response and updating parameters}

The updating process starts with identifying target responses and model parameters to update. In this study the measured first three natural frequencies were taken as target responses to be replicated by the model. It was assumed that the identified frequencies used as targets have a scatter of $2 \%$. The scatter was estimated using the frequencies between $0.0013 \mathrm{~g}$ and $0.0017 \mathrm{~g}$, where there was enough data for very similar PRAs and not affected by the observed frequencyPRA trends (see Figures 5a-c). Therefore, this confidence level was applied to the target responses to define any uncertainty in the experimental data as the diagonal weighting matrix $\boldsymbol{C}_{e}$ entries (Equations (9) and (10)).

The updating parameters were selected based on their expected uncertainty and the sensitivity analysis to determine the most influential parameters to produce a genuine improvement in the model. Only stiffness parameters were considered for updating as mass can normally be determined with less uncertainty. Three parameters, namely: i) shear modulus of soil, ii) modulus of elasticity of cladding, and iii) modulus of elasticity of concrete, were finally selected. Confidence levels were applied to the updating parameters as the diagonal weighting matrix $\boldsymbol{C}_{a}$ entries (Equations (9) and (10)) to take into account uncertainty in their estimation. For this study, it is assumed that the updating parameters can have a scatter within $\pm 30 \%$.

\subsection{Updating of the series of FEMs and discussion}

In this section updating of the series of FEMs, so that they predictions match the selected Points 1 to 5 on the frequency vs. PRA curves, is presented. The first point selected for updating was Point 1 corresponding to the largest PRA of $0.0434 \mathrm{~g}$. (This was chosen as the beginning of the exercise because of the existing experience from preliminary updating attempts that considered only these target frequencies.) The final results of updating at Point 1 were used as the starting 
Return to the Manage Active Submissions page at http://spie.org/app/submissions/tasks.aspx and approve or disapprove this submission. Your manuscript will not be published without this approval. Please contact author_help@spie.org with any questions or concerns.

values for updating at Point 2 and so on moving in the direction of diminishing PRAs and concluding at Point 5. The case of Point 1 updating is described in some detail, while only the final results for all the points are provided due to space limitations.

The target first three modal frequencies for Point 1 obtained from system identification were $3.039 \mathrm{~Hz}, 3.210 \mathrm{~Hz}$ and $3.479 \mathrm{~Hz}$ (Table 3). The initial FEM calculated the first three frequencies as $2.922 \mathrm{~Hz}, 3.451 \mathrm{~Hz}$ and $3.723 \mathrm{~Hz}$. The relative errors between the individual initial FEM and target frequencies did not exceed $7.51 \%$. The overall objective function $e_{f}$ (Equation (11)) was $6.12 \%$. The correlation of mode shapes expressed by MAC values (Equation (3)) was very good, $92 \%$, for the second mode, while for the first and third modes MAC values were reasonably satisfactory being $78 \%$ and $63 \%$, respectively.

In Step 1 of updating, the objective function improved considerably from $6.12 \%$ to $0.31 \%$, and the largest individual error did not exceed $0.32 \%$. In Step 2 of updating, a better solution to that of Step 1 was found among them, suggesting that the above Step 1 solution was only a local minimum and confirming the advantage and need of using the two-step procedure. Step 2 converged to a very small value of $e_{f}=0.03 \%$ for the objective function, providing excellent match of frequencies with the maximum absolute error of $0.05 \%$ (see Table 3 ), and yielding the final updating parameter values of $42.3 \mathrm{MPa}$ for shear modulus of soil, $6.5 \mathrm{GPa}$ for modulus of elasticity of cladding, and $38.4 \mathrm{GPa}$ for modulus of elasticity of reinforced concrete. Compared to the initial values of parameters their relative changes were $-10 \%,-35 \%$ and $28 \%$ for soil, cladding and concrete stiffness, respectively. While MACs were not explicitly included in the objective function, improving frequencies typically also improves MACs. This was also the case in the reported exercise: the MAC values have improved slightly for the first and second mode and are equal to $80 \%$ and $96 \%$, respectively, while for the third mode shape it has improved considerably reaching $78 \%$.

Table 3 and 4 summarize updating results for all the FEMs corresponding to the five points. Table 3 shows frequencies and Table 4 MACs, respectively. It can be seen from Table 3 that updating converged to small values of the objective function not exceeding $0.60 \%$ for all the cases. In fact for four out of five updating cases this number was much smaller, $0.18 \%$. Individual relative frequency errors were in all cases not exceeding $0.94 \%$. MAC values (Table 4 ) were between $80 \%$ and $96 \%$ for the first and second mode, and between $77 \%$ and $86 \%$ for the third mode. These numbers indicate good match between mode shapes. Table 5 shows the initially assumed updating parameters and their final values at each updating point. The final updated values are also shown in Figure 8. These results are now analyses from the following two points of view: i) in any updating exercise it is compulsory to assess the plausibility of numerically obtained results using engineering judgment, ii) the results help to understand and quantify the contributions of structural and nonstructural components as well as soil to the overall stiffness of the building. The first observation that can be made is that all the stiffness parameters show a general decreasing trend with increasing response amplitude. This is consistent with known behavior of materials and structures that normally have 'softening' characteristics. The minimum value of shear modulus of soil for the updated FEMs is $39.6 \mathrm{MPa}$ at Point 2, whereas maximum is $50.4 \mathrm{MPa}$ at Point 5 . The percentage change between the maximum and minimum is $27 \%$. The modulus of elasticity of cladding yielded the minimum value for the updated FEMs of $6.5 \mathrm{GPa}$ at Point 1 , whereas the maximum is $8.2 \mathrm{GPa}$ at Point 3 . The percentage change for the modulus of elasticity of cladding was $26 \%$. The third updating parameter was the modulus of elasticity of reinforced concrete which yielded the minimum value of 38.4GPa at Point 1 and maximum at Point 5 as $45.7 \mathrm{GPa}$, producing the percentage change of $19 \%$. To quantify in a simple way the dependence of the three updating parameters on response amplitude linear regression was performed with PRA of sensor 3 serving as the independent variable. These regression lines are shown in Figures 8a-c. The coefficient of determination, $R^{2}$, also shown in the figures, varies from 0.56 to 0.78 , and confirms that the linear relationship fits the data reasonably well.

Table 3. Summary of updated frequencies for Points 1-5

\begin{tabular}{|c|c|c|c|c|c|c|c|c|c|c|c|c|c|c|c|}
\hline \multirow{3}{*}{ Mode } & \multicolumn{15}{|c|}{ Point } \\
\hline & \multicolumn{3}{|c|}{1} & \multicolumn{3}{|c|}{2} & \multicolumn{3}{|c|}{3} & \multicolumn{3}{|c|}{4} & \multicolumn{3}{|c|}{5} \\
\hline & $\begin{array}{l}f_{e x}{ }^{*} \\
(\mathbf{H z})\end{array}$ & $\begin{array}{c}f_{u}^{\dagger} \\
(\mathbf{H z})\end{array}$ & $\begin{array}{c}e \neq \\
(\%)\end{array}$ & $\begin{array}{l}f_{e x}{ }^{*} \\
(\mathbf{H z})\end{array}$ & $\begin{array}{c}f_{u}^{\dagger} \\
(\mathbf{H z})\end{array}$ & $\begin{array}{c}e * \\
(\%)\end{array}$ & $\begin{array}{l}f_{e x}{ }^{*} \\
(\mathbf{H z})\end{array}$ & $\begin{array}{c}f_{u}^{\dagger} \\
(\mathbf{H z})\end{array}$ & $\begin{array}{c}e \nLeftarrow \\
(\%)\end{array}$ & $\begin{array}{l}f_{e x}{ }^{*} \\
(\mathbf{H z})\end{array}$ & $\begin{array}{c}f_{u}^{\dagger} \\
(\mathbf{H z})\end{array}$ & $\begin{array}{c}e * \\
(\%)\end{array}$ & $\begin{array}{l}f_{e x}{ }^{*} \\
(\mathbf{H z})\end{array}$ & $\begin{array}{c}f_{u}^{\dagger} \\
(\mathbf{H z})\end{array}$ & $\begin{array}{c}e * \\
(\%)\end{array}$ \\
\hline $1^{\text {st }}$ & 3.039 & 3.038 & -0.05 & 3.118 & 3.111 & -0.21 & 3.182 & 3.179 & -0.10 & 3.322 & 3.324 & 0.05 & 3.427 & 3.426 & -0.02 \\
\hline $2^{\text {nd }}$ & 3.210 & 3.211 & 0.02 & 3.399 & 3.377 & -0.65 & 3.491 & 3.488 & -0.09 & 3.549 & 3.547 & -0.05 & 3.650 & 3.641 & -0.24 \\
\hline $3^{\text {rd }}$ & 3.479 & 3.480 & 0.02 & 3.560 & 3.593 & 0.94 & 3.713 & 3.715 & 0.04 & 3.798 & 3.796 & -0.06 & 3.864 & 3.875 & 0.28 \\
\hline \multicolumn{3}{|c|}{ Objective function $e_{f}$} & 0.03 & & & 0.60 & & & 0.08 & & & 0.05 & & & 0.18 \\
\hline
\end{tabular}


Return to the Manage Active Submissions page at http://spie.org/app/submissions/tasks.aspx and approve or disapprove this submission. Your manuscript will not be published without this approval. Please contact author_help@spie.org with any questions or concerns.

Table 4. Summary of updated MACs for Points 1-5

\begin{tabular}{|lllcll|}
\hline \multirow{2}{*}{ Mode } & \multicolumn{5}{c|}{ Point } \\
\cline { 2 - 6 } & $\mathbf{1}$ & $\mathbf{2}$ & $\mathbf{3}$ & $\mathbf{4}$ & $\mathbf{5}$ \\
\hline $\mathbf{1}^{\text {st }}$ & 80 & 80 & MAC (\%) \\
$\mathbf{2}^{\text {nd }}$ & 96 & 94 & 80 & 83 & 96 \\
$\mathbf{3}^{\text {rd }}$ & 78 & 77 & 85 & 81 & 86 \\
\hline
\end{tabular}

Table 5. Initial and final values of updating parameters

\begin{tabular}{|lllllll|}
\hline \multirow{2}{*}{\multicolumn{1}{|c}{ Parameter }} & \multicolumn{5}{c}{ Point } \\
\cline { 2 - 7 } & $\begin{array}{l}\text { Initial } \\
\text { estimate }\end{array}$ & $\mathbf{1}$ & $\mathbf{2}$ & $\mathbf{3}$ & $\mathbf{4}$ & $\mathbf{5}$ \\
\hline Shear modulus of soil (MPa) & 47.0 & 42.3 & 39.6 & 44.6 & 47.6 & 50.4 \\
Modulus of elasticity of cladding (GPa) & 10.0 & 6.5 & 7.5 & 8.2 & 7.8 & 7.8 \\
Modulus of elasticity of reinforced concrete (GPa) & 30.0 & 38.4 & 40.2 & 40.4 & 43.7 & 45.7 \\
\hline
\end{tabular}

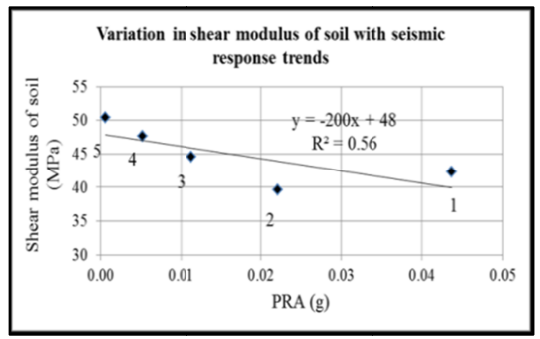

a)

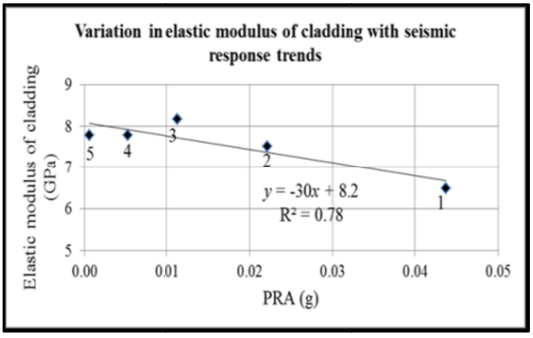

b)

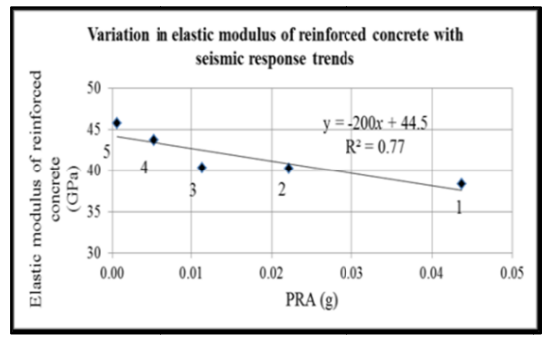

c)

Figure 8. Variation in the updating parameters with PRAs of sensor 3: a) shear modulus of soil, b) modulus of elasticity of cladding, and c) modulus of elasticity of reinforced concrete.

Considering all the five target points, the large drop, up to $35 \%$, in the cladding stiffness from its initially assumed value of $10 \mathrm{GPa}$ indicates that an assumption made in the initial FEM of the cladding being fully fixed to the structural elements was not justified and very likely only partial fixity ever existed. Another reason for reduced stiffness are the openings for windows in the cladding panels which were also ignored in the FEM model. An initial overestimation of cladding material modulus of elasticity, taken from literature, is quite possible too. For the modulus of elasticity of reinforced concrete, there is considerable increase, up to $52 \%$, from the initially assumed value of $30 \mathrm{GPa}$. In situ concrete typically shows significant variability of its properties. Also, the initial estimate of modulus of elasticity of RC was based on typical, conservatively assumed values used in New Zealand building construction of the era but the exact design or laboratory tested values were unknown. For those reasons, the updated values are not unreasonable. It is also possible that other non-structural elements, whose stiffness was not updated, could have made a contribution towards larger stiffness. One would expect more uncertainty in the soils properties, but, perhaps unexpectedly, the change in the soil shear modulus, from its initially assumed value of $47.0 \mathrm{MPa}$, is not large for the five updated values, only up to $10 \%$. The initially assumed value was also between the two extreme values obtained from design.

Finally, for all the parameters it needs to be noted that they are the global stiffness of soil, reinforced concrete and cladding without taking into account any possible local spatial variations. In general, the updated models represent the optimal solution for the frequency matching problem of Equation (11) that are also justified by engineering judgment, but hinge on the validity of the FEM topology, discretization and parameterization. We argue though that these are adequate.

\section{CONCLUSIONS}

This study comprises of two parts. The first part involves the evaluation of seismic responsie trends of an RC building using state-of-the-art N4SID system identification technique. The frequencies showed a clear decreasing trend with increasing PRA which could be reasonably represented by bi-linear relationships. The damping ratios had scattered 
Return to the Manage Active Submissions page at http://spie.org/app/submissions/tasks.aspx and approve or disapprove this submission. Your manuscript will not be published without this approval. Please contact author help@spie.org with any questions or concerns.

values with no clear trend. The second part was concerned with numerical modeling of the building and sensitivity based model updating for the seismic response trends observed in the first part of the study. A series of FEMs were updated to replicate the varying behavior of the building under seismic excitations. The updating parameters included the stiffness of concrete, cladding and soil. Excellent matches of frequencies were achieved, with average errors not more than $0.60 \%$. The updating parameters were found to generally follow decreasing trends and changed in the considered range of PRA by $19 \%$ for concrete, $26 \%$ for cladding, and $19 \%$ for soil, respectively.

\section{ACKNOWLEDGEMENTS}

The authors would like to thank their supporters. GeoNet staff, particularly Dr Jim Cousins, Dr S.R. Uma and Dr Ken Gledhill, helped with access to seismic data and building information. Faheem Butt's PhD study was funded by Higher Education Commission (HEC) Pakistan. Piotr Omenzetter's work within The LRF Centre for Safety and Reliability Engineering at the University of Aberdeen is supported by The Lloyd's Register Foundation (The LRF). The LRF supports the advancement of engineering-related education, and funds research and development that enhances safety of life at sea, on land and in the air.

\section{REFERENCES}

1. Celebi, M., "Recorded earthquake responses from the integrated seismic monitoring network of the Atwood Building, Anchorage, Alaska," Earthquake Spectra 22(4), 847-864 (2006).

2. Satake, N., and Yokota, H., "Evaluation of vibration properties of high-rise steel buildings using data of vibration tests and earthquake observations," Journal of Wind Engineering and Industrial Aerodynamics 59(2-3), 265-282 (1996).

3. Trifunac, M. D., Ivanovic, S. S., and Todorovska, M. I., "Apparent periods of a building. I: Fourier analysis," Journal of Structural Engineering ASCE 127(5), 517-526 (2001).

4. Brownjohn, J. M. W., and Xia, P. Q., "Dynamic assessment of curved cable-stayed bridge by model updating," Journal of Structural Engineering ASCE 126(2), 252-260 (2000).

5. Farrar, C. R., Sohn, H., and Doebling, S. W., "Structural health monitoring at Los Alamos National Laboratory," US-Korea Conference on Science and Technology, Entrepreneurship and Leadership, Chicago, Illinois, 1-11 (2000).

6. Trifunac, M. D., and Todorovska, M. I., "Recording and interpreting earthquake response of full-scale structures," Proc. NATO Advanced Research Workshop on Strong-Motion Instrumentation for Civil Engineering Structures, Kluwer Academic Publications 131-155 (1999).

7. Bhattacharya, K., and Dutta, S. C., "Assessing lateral period of building frames incorporating soil flexibility," Journal of Sound and Vibration 269(3-5), 795-821 (2004).

8. Su, R. K. L., Chandler, A. M., Sheikh, M. N., and Lam, N. T. K., "Influence of non-structural components on lateral stiffness of tall buildings," Structural Design of Tall and Special Buildings 14(2), 143-164 (2005).

9. Van Overschee, P., and De Moor, B., "N4SID: Subspace algorithms for the identification of combined deterministic-stochastic systems," Automatica 30(1), 75-93 (1994).

10. Van Overschee, P., and De Moor, B., Subspace identification for linear systems, Kluwer Academic Publishers, Dordrecht, Netherlands (1996).

11. Ewins, D. J., Modal testing: Theory, practice and application, Research Studies Press, Baldock, Hertfordshire, UK (2000).

12. Stewart, J. P., and Fenves, G. L., "System identification for evaluating soil-structure interaction effects in buildings from strong motion recordings," Earthquake Engineering and Structural Dynamics 27(8), 869-885 (1998).

13. Montgomery, D., Peck, E. A. and Vining, G., Introduction to linear regression analysis, Wiley, New York (2001).

14. Steel, R. and Torrie, J., Principles and procedures of statistics, McGraw-Hill, New York (1960).

15. Brownjohn J. M. W., Moyo P., Omenzetter P., Lu Y., "Assessment of highway bridge upgrading by dynamic testing and finite element model updating," Journal of Bridge Engineering, ASCE 8(3), 162-172 (2003).

16. Wu, J. R., and Li, Q. S., "Finite element model updating for a high-rise structure based on ambient vibration measurements," Engineering Structures 26(7), 979-990 (2004).

17. Dynamic Design Solutions, FEMtools for Windows, Dynamic Design Solutions, Leuven, Belgium (2001).

18. Dascotte, E., Strobbe, J., and Hua, H., "Sensitivity based model updating using multiple types of simultaneous state variables," Proceedings of the 13th International Modal Analysis Conference, Bethel, USA, 1-6 (1995).

19. Brownjohn, J. M. W., Xia, P.-Q., Hao, H., and Xia, Y., "Civil structure condition assessment by FE model updating: methodology and case studies," Finite Elements in Analysis and Design 37, 761-775 (2001). 
Return to the Manage Active Submissions page at http://spie.org/app/submissions/tasks.aspx and approve or disapprove this submission. Your manuscript will not be published without this approval. Please contact author_help@spie.org with any questions or concerns.

20. Kanvinde, A. M., and Deierlein, G. G., "Analytical models for the seismic performance of gypsum drywall partitions," Earthquake Spectra 22(2), 391-411 (2006).

21. Gaylord, M. W., Reinforced plastics: Theory and practice, 2nd Edition, Cahners Publishing Co., New York (1974).

22. Gazetas, G., "Formulas and charts for impedances of surface and embedded foundations," Journal of Geotechnical Engineering, ASCE 117(9), 1363-1381 (1991).

23. Standards New Zealand, Structural design actions. Part 5: Earthquake actions - New Zealand, Standards New Zealand, Wellington, New Zealand (2004).

24. Boon, D., Perrin, N. D., Dellow, G. D., Van Dissen, R., and Lukovic, B., "NZS1170.5:2004 Site subsoil classification of Lower Hutt," Proceedings of the 2011 Pacific Conference on Earthquake Engineering, Auckland, New Zealand, 1-8 (2011). 